\title{
Trends and Mechanisms of Digital Transformations in the Russian Federation
}

\author{
Armashova-Telnik G.S.* \\ Department of Program and Target Management in \\ Instrument Engineering, St. Petersburg State University \\ of Aerospace Instrumentation, \\ St. Petersburg, Russia \\ atgs@yandex.ru
}

\author{
Melnichenko A.M. \\ Faculty of Continuing Professional Education, \\ St. Petersburg State University of Aerospace \\ Instrumentation, St. Petersburg, Russia \\ atgs@yandex.ru
}

\author{
Terentyeva Yu.G. \\ Department of Program and Target Management in Instrument Engineering, \\ St. Petersburg State University of Aerospace Instrumentation, \\ Saint-Petersburg, Russia \\ atgs@yandex.ru
}

\begin{abstract}
The article is devoted to the issues of digitalization of a business entity model. Prospects for the development of technological transformations in Russia are highlighted, key positions of the integration of digital modernization in the business sector are analyzed, including the specific nature of implementation processes, relevant experience in the business sector (in accordance with industry affiliation), which provides an opportunity for business entities to increase the efficiency of production operations. High importance of the implementation of digital technologies in production and their impact on the country's economy was noted.
\end{abstract}

Keywords - digital transformations, modernization of production, efficiency, integration of digitalization technologies.

\section{INTRODUCTION}

Digital transformation is a set of transformations of an organization, including changing business models based on new technological capabilities. Transformation involves not only investments in new technologies (artificial intelligence, blockchain, data analysis and the Internet of things), but also a deep transformation of products and services, organization structures, development strategies, customer service and corporate culture. In other words, this is a revolutionary transformation of the organization model. Digital transformation is needed for those businesses that are not yet in digital or that have not been created initially in digital

Orientation of digital transformations in the process of functioning of business entities implies a high degree of mobility in the implementation of management decisions, optimization of adapted responses to production challenges, and the needs of the target audience. The failure of the business structure to integrate relevant technological solutions into the functioning processes of its activities does not allow the company to build a competitive model of the business entity, unlike enterprises that implement innovative technological offers in industry markets.
Digitalization technologies of production processes are a certain guarantor of the formation of an effectively personalized interaction relevant to the target audience. Digital communication channels, artificial intelligence, and robotics are naturally included elements in all life processes. Customers are the driving force behind digitalization. Every day, the target audience carries out interconnections of various nature with commercial and state structures that already implement digitalization technologies in practice. What determines the client's vision of the advantages of business processes based on the application of relevant technological solutions over the lack thereof. The experience of the target audience includes communication with industrial partners of the enterprise.

We emphasize that the digitalization of technological processes provides an increase in the efficiency of human resource productivity in the organization, which in turn increases the efficiency of the enterprise as a whole (for example, the automation of a number of technological operations optimizes production processes at the enterprise). Note that in accordance with the predicted development options for IDC, the costs of integrating digital technologies on a global scale for 2019 amounted to about \$ 2 trillion. More than $70 \%$ of business entities report the presence of an implemented digital strategy (including the development of its integration into activities)

\section{METHODS AND MATERIALS}

Digital transformation makes fundamental changes in the structure of business processes based on information, which necessitates the implementation of multidimensional analysis (collection) of data from both the external and internal environment of the enterprise for their subsequent accumulation, aggregation, visualization. Here, substantial support is provided by platforms equipped with artificial intelligence algorithms, which allows analyzing billions of information data in the online format, classifying them, grouping them, segmenting them and presenting them in an 
ergonomic way on the Dashboard. As part of the further development of digitalization, it is planned to intensify the use of chatbot and other technologies that provide automation of customer service, one of the key elements of digital transformation.

According to Spiceworks research, more than $40 \%$ of large enterprises included in the strategic plans of their development the tasks of integrating their own chatbot, consistently achieving the goal. Actual hatbot involves not just fixing the clients' appeals, but also determining their psychoemotional state, which will provide the opportunity for adapted communication, the corresponding correction of their own data (knowledge) in real time through coordinated procedures with multi-channel similar sites. In addition, the evolutionary achievements of technological processes of speech analyzers will provide, in the future, effective communication with both voice assistants (Alex, Siri) and a similar virtual assistant (food industry, e-commerce, etc.). Also, one can predict the accentuation of a personalized relationship with a client, which enhances the competitiveness of a business entity by converting a client base. At the same time, it is assumed personalization of both business structures and Internet spaces (enterprise sites), in connection with which the client forms an awareness of communication with key brands directly.

The important function in personalization is given to artificial intelligence technologies, the use of which ensures the receipt, recording and analysis of data through all communication channels with the target audience in online format (including analysis of events (purchases), individual characteristics, etc.)

The important function in personalization is given to artificial intelligence technologies, the use of which ensures the receipt, recording and analysis of data through all communication channels with the target audience in online format (including analysis of events (purchases), individual characteristics, etc.), minimizing labor costs during formation individual offers for the consumer. In connection with the implementation of artificial intelligence technologies (combining demographic, emotional-behavioral and historical data), additional values are being increased for both business entities and the target audience.

Business structures that position themselves in the field of digital transformation as dominants strive to integrate the zerotouch-automation model in the business sector (in addition to personalization), within the framework of which the process of absolute automation is implemented - excluding human participation. Internet of Things (IoT) technologies, augmented reality and unmanned vehicles, multi-cloud companies have already become part of everyday life. The business sector needs a conscious understanding of the appropriateness of continuous development processes, the development of strategic areas of technological breakthroughs to maintain and grow competitive positions.

The Basics of Introducing Digital Transformation into Business:
1) Identification of the essence of the business and the prospects for its development, business priorities, business requirements for IT;

2) The selection of appropriate new IT-technologies. Analysis of the possibilities of new IT technologies;

3) Analysis of the current state of IT (information systems, IT infrastructure, IT management);

4) Accounting for the size of the company, industry, other features;

5) Identification of those responsible for the digital transformation of the business;

6) Defining the scope of a project for digital business transformation: time, money, people, methods, elements of IT and business;

7) Development of a digital business transformation strategy.

The specifics of digital transformation [1-3]

1) Digital transformation is a change in current business practices in the field of decision-making, which are either taken by a person on the basis of data analysis, or exclude a person from the process.

2) Algorithms allow not only to accelerate and improve processes in current business models, but also to create new business models, such as ecosystem, platform businesses.

3) New models based on the use of data analytics allow offering a huge selection, personalization, speed and low cost on a scale that is not available to traditional companies.

4) For digital transformation, we can not use only one technology or digitize one business process. An integrated approach to the use of information technology in all processes of the company is required, not only internally, but also when interacting with the outside world, customers, partners and the state.

Issue:

1. Administrative problems - inconsistency of the current industry regulation with the needs of the new technological structure, lack of uniform standards.

2. Information - lack of information on digital transformations and their capabilities, distrust of technologies and the benefits of their implementation in enterprises.

3. Personnel - lack of personnel. At the current stage, staff shortages are not considered as a critical problem of digital technologies, experts agree that with the development of digital transformations, this problem will become increasingly widespread.

4. Financial - lack of funds for the implementation of the project.

5. The issue of motivation for senior staff, digital literacy of the middle and upper level management in enterprises. Psychological barriers and unreasonable conservatism. 
6. Innovations in the technological field are poorly supported by innovations in the field of economics and management.

Successfully implemented new technological capabilities for working with information and information (digital) entities bring not only improvements to the enterprise, but also new threats: for the organizational structure, for operational activities (cyber security), for making managerial decisions.

\section{RESULTS}

Digital Transformation Implementation Example

Autonomous Non-Profit Organization (ANO) "Digital Economy" (Fig. 1.2)

The organization was created to provide services in the field of digital economy development in the Russian Federation, by supporting socially significant projects and initiatives in this field, as well as coordinating interaction between business in the digital economy, scientific and educational organizations, other communities and authorities. By 2024, one of the directions of the state strategy is the implementation of the economic digitalization of Russia (including the social sphere)

By 2024, one of the directions of the state strategy is the implementation of the economic digitalization of Russia (including the social sphere). That actualizes the need for the development of relevant legislative and regulatory documents (integration of digital technologies), the modification of the digital space, the construction of mechanisms for digital practical application in the country's economy (including the state administration apparatus), and the development of algorithms for the formation of human capital during the transition period.

Currently, as part of the functioning of the Digital Economy platform, discussions are being held on proposals, benchmarks, mechanisms for more than a thousand decisions by experts from various sectors of the business sector, government, scientific organizations, which is aimed at achieving Russia's goal of becoming one of the world leaders in the field of technological development.

Here, the business sector forms strategic development directions, evaluates the potential effectiveness of the implementation of programs and action plans, makes suggestions on the content of the program and action plans. The working group prepares proposals for design solutions of plans, recommendations for the correction of plans, if necessary. As part of the exercise of its authority, the Competence Center ensures the accumulation of decisions in the draft plan, implements an action plan.

In the framework of the implementation of the Federal projects and National programs, conditions of an institutional and infrastructural nature are created, the elimination of existing obstacles and restrictions for the creation and development of high-tech guidelines for entrepreneurial activity is carried out in six areas:

1) Personnel for digital economy.

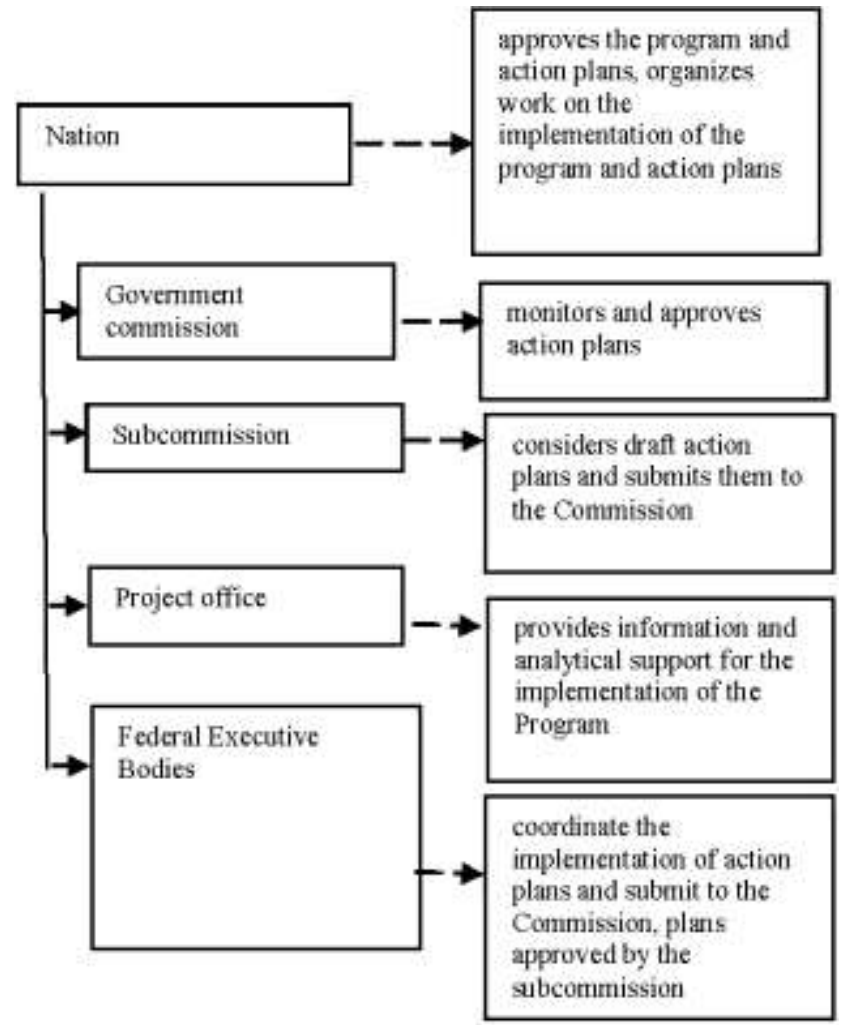

Fig. 1. Program structure

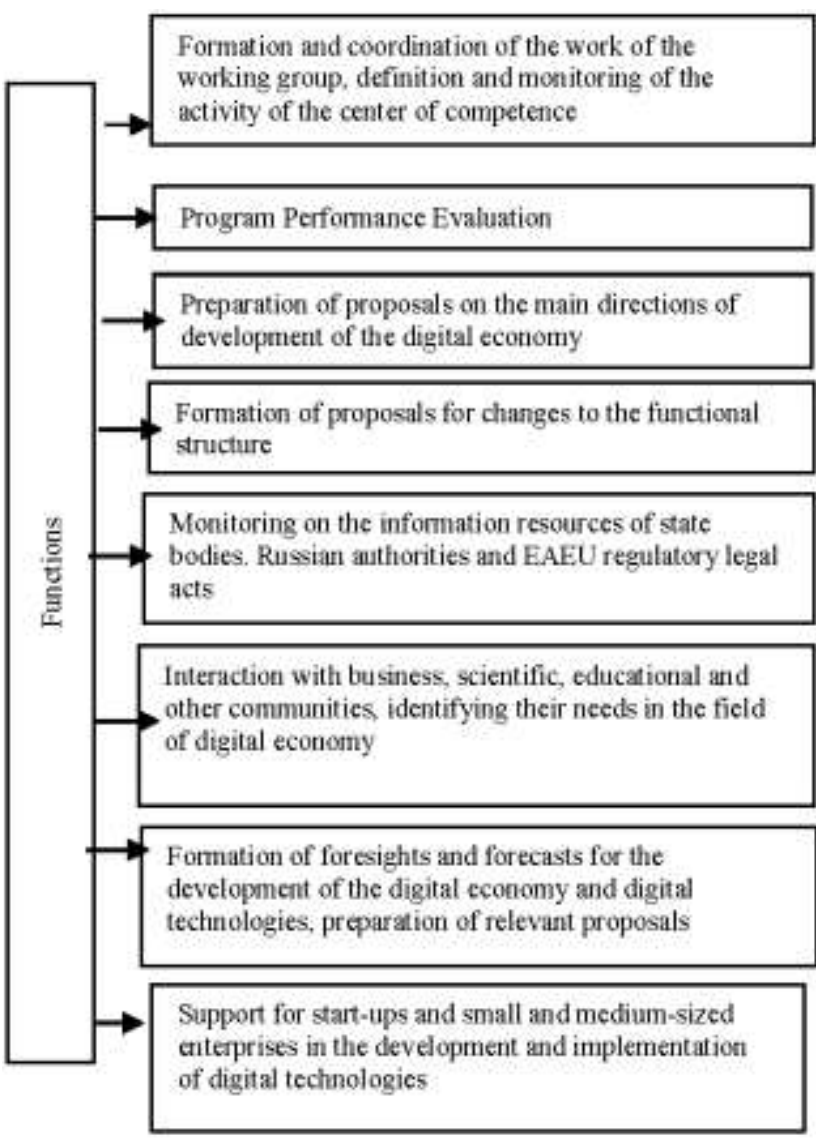

Fig. 2. the functions of the structural elements of programs 
Improving the education system, which should provide the digital economy with competent personnel. The transformation of the labor market, which should be based on the requirements of the digital economy. Creation of a motivation system for the development of the necessary competencies and the participation of personnel in the development of the digital economy of Russia.

The task of the direction:

- 120,000 people a year - graduates of educational institutions of higher education in areas of training related to information and telecommunication technologies;

- 800,000 people per year - the number of graduates of higher and secondary prof. education with competencies in the field of information technology at the global level;

- $40 \%$ share of the population with digital skills.

Competence Center: 20.35 University of the National Technology Initiative.

2) Information infrastructure.

Development of communication networks, development of a system of Russian data centers, the introduction of digital data processing platforms to meet the needs of citizens, business and government.

Tasks of the direction:

- $97 \%$ - the share of households with broadband Internet access in the total number of households;

- $100 \mathrm{Mbps}$ - stable coverage throughout the country;

- $5 \mathrm{G}+-$ sustainable coverage in all major cities.

Competence Center: Rostelecom

3) Information Security

Achieving the state of protection of the individual, society and the state from internal and external information threats, which ensures the realization of constitutional rights and freedoms of man and citizen, worthy quality and standard of living of citizens, sovereignty and sustainable socio-economic development of the Russian Federation.

Tasks of the direction:

- $50 \%$ - the proportion of citizens who have improved literacy in the field of information security, media consumption and the use of Internet services

- $97 \%$ of the population who used the means of protecting information from the total population who used the Internet over the past 12 months

- $75 \%$ share of entities using standards of safe information interaction between state and public institutions;

Competence Center: Sberbank.

4) Digital technology.
Formation of a mechanism for the comprehensive support of research (search, applied) in the field of the digital economy, providing technological autonomy individually, in areas of related digital technologies highly sought after at the world level (including national security issues)

Tasks of the direction:

- 30 completed projects in the field of the digital economy (at least 100 million rubles)

- 10 Russian organizations involved in the implementation of large projects (\$3 million) in priority areas of international scientific and technical cooperation in the field of digital technologies

"Cross-cutting technologies" - are promising revolutionary technological solutions, the result of which is the restructuring of market conditions, as well as the creation of new market benchmarks.

Direction tasks:

- Big info

- Neurotechnology and artificial intelligence

- Distributed Registry Systems

- Quantum technology

- New manufacturing technologies

- Industrial Internet

- Robotics and sensor components

- Wireless Technologies

- Virtual and Augmented Reality Technologies

Competence Center: ROSATOM, Rostec

Normative regulation is ensured by the formation of a new regulatory environment, providing for a favorable legal regime for the emergence and development of modern technologies, as well as for the implementation of economic activities related to their use.

\section{Competence Center: Sk Skolkovo.}

In terms of digital public administration, digital technologies and platform solutions are being implemented in the areas of public administration and the provision of public services, including in the interests of the population and small and medium-sized enterprises, including individual entrepreneurs

Tasks of the direction:

- $70 \%$ of interactions between citizens and commercial organizations with government bodies and budget institutions are carried out digitally

- $100 \%$ of priority public services and services are provided without the need for a personal visit to government bodies and other organizations, using the registry model, online 
- $70 \%$ of the master data has been harmonized (compliance with master data)

- $90 \%$ of interdepartmental and interdepartmental legally significant electronic document management of state and municipal bodies and budgetary institutions

Center of Competence: Analytical Center for the Government of the Russian Federation

Application of Digital Transformation in Various Industries.

\section{A. Financial services}

In order to feel confident in changing financial markets, serve customers, fight fraud, maintain compliance rules, financial institutions need solutions for consolidating data traditionally managed at the departmental level and allowing creating corporate storage with analytics support available in self-service mode.

Examples of financial solutions:

1) the prevention of fraud in the issuance of loans and payments;

2) modeling of risks in investment banking;

3) cross-selling and increasing sales in retail banking services;

4) the introduction of new financial products;

5) personalization of insurance policy;

6) assessment of the mortgage loan portfolio.

\section{B. Production area}

Manufacturers collect a huge amount of data related to the production of product components, their further use, as well as production processes and supply chains. Today, in the era of the Internet of Things, manufacturers 'data management challenges are growing as products constantly generate data related to their performance, functionality and quality. The task is not only to capture all this data, but also to manage it, as well as analyze it to generate information about products and processes.

Examples of solutions in production:

1) predictive quality assurance;

2) analysis of demand for new products and services;

3 ) detection of problems with the supply chain;

4) identifying opportunities for the development of new value-added services.

\section{Oil and gas production}

Oil and gas companies need to accelerate the discovery and extend the life of existing fields by increasing the efficiency of their recovery. A huge amount of data is required to increase production and minimize non-productive time (NPT). The problem is that traditional data processing technologies do not allow efficient processing of large amounts of information [5-9]. This leads to the creation of many small repositories, and as a result, it can take months to obtain useful information based on this data.

Examples of solutions for the oil and gas industry:

1) exploration data processing;

2) forecasting the technical condition to increase uptime.

\section{Retail industry}

To compete in the age of online stores, to better understand their customers and increase the efficiency of their operations, large retailers need scalable information management systems that combine online and offline data.

In particular, retailers now need to connect and process data in many formats from disparate systems and sources, including social networking sites that consumers interact with.

Examples of using analytics solutions in retail:

1) the possibility of 360 degree customer vision;

2) the creation of personalized offers;

3) analysis of merchandising and supply chains;

4) unified customer identification in all operating systems;

5) management of the loyalty program;

6) analysis of customer churn.

\section{E. Telecommunications \& Service Providers}

Telecommunications service providers today are among the largest consumers of big data. Data analytics is one of the ways to identify and understand the development trends of network services, reduce infrastructure costs, increase the average revenue per user, expand service offerings, improve the quality of customer service and prevent their churn. In traditional environments, customer information is recorded in different systems [10]. Such fragmentation makes it difficult for providers to analyze data that would provide a holistic, consolidated view of subscribers. Data sources in disparate systems do not provide easy access and can not be fully analyzed to identify market opportunities, target new service offers and achieve other business goals.

Examples of using analytics solutions in telecom:

1) the definition of new market opportunities for targeted services;

2) joint planning and forecasting;

3) planning network capacity, trends and network management;

4) prioritization of network infrastructure based on demand;

5) prevention of customer churn;

6) determining the quality of service for subscribers;

7) research and development based on machine data;

8) bandwidth optimization. 
Regardless of industry, the organization's IT service plays a key role in creating a secure and universal collaboration environment that is needed for the transparent integration of technologies, personnel and digital transformation processes. We name the main components of a reliable digital platform:

1) Verified data received in real time.

2) Effective analytics and knowledge that maintain high standards of doing business.

3) Continuous optimization of IT and operational technology costs combined with a high degree of flexibility.

4) A culture of innovation that spans the entire organization.

\section{CONCLUSION}

In this way, digital transformation spans every industry. Business moved to a new level of development - industry 4.0. Well-established companies need a complete rethinking of starting a business - otherwise they will be left out of the modern economy. The time has come for inventions and discoveries in the field of management and economics. Creation of methodologies for new business models based on the use of data analytics is required. Special attention is required to adapt economic security to modern cyber threats. To achieve the goal of digital transformation, using only one technology or digitizing one business process will not be enough. Digital transformation is a comprehensive approach to the use of IT in all processes of the company, and not only within the company, but also when interacting with customers, partners, and especially with the state. Further training is required for employees at all levels. The implementation of digital technology requires tremendous work on digitalization with a huge amount of data. Although Russia lags behind the leading countries, we have our own vision of digitalization of business processes and the main understanding of the required changes.

\section{References}

[1] V.A. Plotnikov, "Digitalization of production: theoretical essence and development prospects in the Russian economy", News of St. Petersburg
State Univer. of Econ., vol. 20, no. 2, 2018. Retrieved from: /// C: / Users $1 \% \mathrm{D} 0 \% 93 \% \mathrm{D} 0 \% \mathrm{~B} 0 \% \mathrm{D} 0 \% \mathrm{BB} \% \mathrm{D} 0 \% \mathrm{~B} 8 \% \mathrm{D} 0 \% \mathrm{BD} \% \mathrm{D} 0 \% \mathrm{~B} 0 / \mathrm{D} o w n l o a$ ds / tsifrovizatsiya-proizvodstva-teoreticheskaya-sushnost-i-perspektiv razvitiya-v-rossiyskoy-ekonomike\%.

[2] E.V. Maimina, T.A. Puzyna, "Features and Trends in the Development of the Digital Economy", Bull. of the Univer. of Cooperat., Econ. and Law, no. 6, 2017. Retrieved from: https://www.elibrary.ru/download/elibrary_30607018_27290780.

[3] M.A. Averyanov, O.V. Baranova, E.Yu. Kochetova, R.L. Sivakov, Digital transformation of regulatory processes: trends, approaches and solutions. Moscow: LLC "CIT". Retrieved from: https://cyberleninka.ru/article/n/tsifrovaya-transformatsiya-protsessovnormativnogo-regulirovaniya-tendentsii-podhody-i-resheniya

[4] N.N. Muravyova, N.S. Talalaeva, "Assessment of target values of indicators of financial management effectiveness in small and mediumsized enterprises, taking into account industry and regional specifics", Bull. of the Voronezh State Univer. of Engineer. Technol., vol. 81, no. 2, pp. 290-300, 2019. Retrieved from: https://doi.org/10.20914/2310-12022019-2-290-300/

[5] Yu.V. Zhuravlev, I.V. Kuksova, E.A. Hubertov, L.I. Churikov, "Assessment of the innovative development of the Russian Federation based on indicators of the concept and strategy of 2020", Bull. of the Voronezh State Univer. of Engineer. Technol., vol. 81, no. 2, pp. 377-382, 2019. Retrieved from: https://doi.org/10.20914/2310-1202-2019-2-377382

[6] Yu.A. Salikov, I.V. Logunova, I.V. Kablashova, "Trends in changes in the human resources management of an enterprise in a digital economy", Bul. of the Voronezh State Univer. of Engineer. Technol., vol. 81, no. 2, pp. 393-399, 2019. Retrieved from: https://doi.org/10.20914/2310-12022019-2-393-399

[7] N.A. Serebryakova, I.V. Avdeev, "The content of structural transformations of the region's economy, adequate to the requirements of digitalization", Bull. of the Voronezh State Univer. of Engineer. Technol., vol. 80, no. 4, pp. 408-412, 2018. Retrieved from: https://doi.org/10.20914/2310-1202-2018-4-408-412

[8] I.A. Zubritskaya, "An Analysis of the World Experience in Digital Transformation of Industry: An Institutional Model", Digital transformat., no. 1, pp. 21-35, 2019. Retrieved from: https://dt.giac.by/jour/article/view/141

[9] P.A. Levchaev, B. Hezazna, "Transformation of managerial technologies in the digital economy", Digital transformat., no. 3, pp. 39-47, 2019. Retrieved from: https://dt.giac.by/jour/article/view/273

[10] I.G. Salimyanova, A.S. Pogoreltsev, "Digital transformation of the economy: analysis of trends in the context of institutional economic theories", News, no. 6-2018, part 1. Retrieved from: https://cyberleninka.ru/article/n/tsifrovaya-transformatsiya-ekonomikianaliz-trendov-v-kontekste-institutsionalnyh- ekonomicheskih-teoriychast-1 